\title{
Birthing New Kinships: The Cross-Pollinating Potential of Amish Health Research
}

\author{
Natalie Jolly ${ }^{1}$ \\ Assistant Professor \\ School of Interdisciplinary Arts and Sciences \\ University of Washington, Tacoma
}

\begin{abstract}
In this article, I explore the connections between Amish gender socialization and Amish birth practices to suggest that an Amish construction of femininity shapes the ways that Amish women experience childbirth. This study is framed by Amish women's health research and takes as a point of departure two observations often made about Amish childbirth practices: (1) medical research has found that Amish women have shorter labors than their non-Amish (English) counterparts, and (2) doctors, midwives, and birth attendants have argued that Amish women's expression of pain during labor and delivery differs substantially from their English counterparts. I draw on my two years of ethnographic work on Amish midwifery and homebirth to argue that there is deep sociological richness in medical findings that often dismiss Amish life as merely culturally anomalous. I argue that Amish birth is shaped by the norms of Amish society, particularly those that govern gender. I conclude that many of the features of Amish birth that have so interested health researchers cannot be fully understood without a sociological investigation of Amish life, and plain Anabaptist scholarship seems well positioned to foreground the social and cultural features of Amish society that likely remain invisible to health researchers. Reciprocally, comparative health studies on the Amish may illuminate areas of inquiry that were previously understudied and offer new possibilities for future social and cultural research within plain Anabaptist studies.
\end{abstract}

\section{Keywords}

Childbirth; Amish women’s health; Homebirth; Ethnography; Health sociology

\section{Acknowledgements}

I am grateful to the many Amish women who shared their homes, their lives, and their births with me and to Cory Anderson for his ongoing enthusiasm and support. 


\section{Introduction}

Medical research has long featured comparative work investigating health disparities between Amish and English populations. Researchers have inquired into a range of topics, spanning the Amish's relatively low rate of diabetes (Hairston, et al. 2013) and cancer (Katz, et al. 2012) to their propensity to more quickly recover from traumatic injury (Rogers, et al. 2013). What threads the myriad Amish health studies together is both their conclusion that significant differences in health patterns exist between Amish and non-Amish populations and the subsequent assertion that these differences result from "social support” (Documét, et al. 2008, 65) or even "lifestyle differences" (Lucas, et al. 1991, 49) fostered by "the unique social structure of the Amish population” (Rogers, et al. 2013, 916). I suggest here that while such health and medical studies offer cursory observation of the cultural peculiarisms of Amish society, they do little to investigate the structure of Amish society in ways that are meaningful for our understanding of how socialization shapes the health and wellness of the body.

I begin by reviewing some of the significant work being done on Amish women's health, as this has been one of the primary sites of medical inquiry. I focus specifically on research that concerns Amish childbirth practices and make two observations: (1) medical research has found that Amish women have shorter labors than their non-Amish (English) counterparts, and (2) doctors, midwives, and birth attendants have argued that Amish women's expression of pain during labor and delivery differs substantially from their English counterparts. As a way to move beyond classifying these findings as mere cultural anomalies, I offer my ethnographic work on Amish midwifery and homebirth to suggest that these cursory observations come into sharp focus when viewed through a sociological lens. I present findings from my two years of ethnographic research on Amish homebirth in conjunction with an analysis of Amish culture to argue that Amish socialization has bodily consequences: being Amish shapes you, mind and body. I explore the connections between Amish gender socialization and Amish birth practices to suggest that an Amish construction of femininity shapes the ways that Amish women experience childbirth. I conclude by positing that the nuanced social, cultural, and historic work being undertaken by Anabaptist scholars has much to offer the growing literature on Amish health and medicine. If we are to fully appreciate how better health outcomes grow out of Amish society, we need to fully account for the connection between social structure, cultural landscape, and the physical body. Plain Anabaptist scholars are well positioned to offer that insight. Reciprocally, comparative health studies on the Amish may illuminate areas of inquiry that were previously understudied and offer new possibilities for future social and cultural research within the field of plain Anabaptist studies.

\section{Looking at Amish Women's Reproductive Health}

Health and medical research has considered Amish women's lives from childhood through menopause and beyond (Documét, et al. 2008; Hairston, et al. 2013; Hewner 2001; McArdle, et al. 2006; Miller, et al. 2007; Thomas, et al. 2002; Von Gruenigen, et al. 2000). 
Within this tradition, there has been a sustained focus on childbirth practices (Bing 2002; Campanella, Korbin, and Acheson 1993; Kroening 2008; Miller, et al. 2007; VonDerAhe 1998). Such academic interest is likely motivated by Amish women's preference for home delivery, coupled with the low levels of medical intervention their births necessitate. Regional variation exists, but overall Amish women are less likely than their non-Amish counterparts to use hospital-based obstetric services for their prenatal care and delivery and have higher rates of midwife-attended homebirth (Cox, et al. 2013). This presents a unique vantage point for research, as only $1 \%$ of all births in the United States take place outside of a hospital facility (Jolly 2010). As a result, Amish women and their childbirth practices have been a source of fascination for the mainstream obstetric medical community as well as the alternative homebirth/midwifery community. Below, I present two culturally significant features of Amish women's childbirth practices discussed in medical research and suggest that they warrant a more robust sociocultural analysis than has conventionally been offered by the health research community.

Comparative childbirth scholarship has found two features of Amish women's childbirth practices to be of interest: Amish women's shorter duration of labor and their higher likelihood of laboring without pain medication. In one of the first studies to quantify the impact of Amish "life style differences" (Lucas, et al. 1991, 49) on pregnancy outcomes, Lucas, et al. hypothesized a lack of smoking and alcohol use coupled with a higher level of physical fitness would manifest in healthier Amish babies. ${ }^{2}$ And while the authors did not find Amish babies to be healthier than their non-Amish counterparts per se, they did find that Amish women were having significantly shorter labors. A surprising three hour difference was documented, with Amish women averaging seven hours of labor while their non-Amish counterparts averaged ten hours. Others have similarly noted that "[Amish] labors tend to be shorter than average" (Showalter 2000, 11). In conjunction with this, researchers have also drawn attention to Amish women's lower levels of expressed pain in labor (Keeslar 2011), their relative lack of discomfort in labor (Williams 2003), and their avoidance of pain medication during labor (Deline, et al. 2012) as compared to non-Amish women in childbirth. With their quick deliveries and stoic approach to pain, Amish women are seen to not "make a fuss in labor" (Showalter 2000, 10). And while health researchers have noted these differences in childbirth practices, they are less well-positioned to offer thoughtful sociocultural analyses of the findings they have uncovered. Indeed much of this research concludes with a general nod to the vagaries of Amish culture without a systematic investigation of how Amish culture intersects with particular childbirth practices. For instance, Miller (1997) concludes her observation of Amish childbirth by suggesting that, "It is not always clear as to what cultural factors influence Amish women in these childbearing health practices" (p. 4), and Lemon (2006) posits that, "Culture exerts a great influence on the perinatal family" (p. 58) without detailing what that influence may entail. Plain Anabaptist scholars would certainly agree that, "The Amish community is a unique culture" (Weyer, et al. 2003, 139), but without marrying specific health and childbirth findings to a deeper 
analysis of Amish history, culture, and social structure, we are unable to adequately understand how Amish bodies are shaped by Amish society.

\section{An Ethnography of Amish Childbirth}

The repeated observation that Amish women birth differently, and according to the health researchers cited above-birth better — was, for me, a siren song as a sociologist interested in understanding how culture shapes experiences. My goal in this ethnographic analysis is to both offer a sociological response to the existing health research findings discussed above and to demonstrate how heath research may illuminate understudied areas of plain Anabaptist research. My findings stem from a two-year-long ethnographic study on midwifery and homebirth in several Pennsylvania Old Order Amish communities. This ethnographic inquiry was structured as a two-year participant observation with a non-Amish midwife who served several conservative Old Order church districts in the valleys of central Pennsylvania (Jolly 2014a). The church districts we served were conservative horse and buggy Old Order Amish, and women wore tight buns topped with gossamer bonnets (black felt bonnets during the winter) and dark blue or green dresses with a white apron held to the front by a series of straight pins. Clients were both first-time mothers and multiparous, ranging in age from 18 to 41. During 2003 to 2006, I spent 30 months as an apprentice midwife and volunteer healthcare worker. Despite having no formal medical training, I undertook the conventional lay midwife apprentice-training program: attending 40 Amish homebirths as well as several hundred prenatal and postpartum visits and serving as birth assistant to a lay midwife who had been delivering Amish babies for 20 years. As a result, much of my data collection happened through active participation in Amish pregnancy and birth care.

As an apprentice midwife, I was called upon to provide support during labor and delivery as well as prenatal and postpartum care to Amish women and their families. In this capacity, I became familiar to the women that we served and was able to observe their prenatal, postpartum, and childbirth practices, as well as informally discuss their thoughts about and approaches to the upcoming delivery. My active participation legitimized my presence in the Amish communities we served and occasioned a relationship built on mutual support and reciprocity. Participation in this research project was voluntary. Participant-observational data allowed me to draw on local phenomena to inform a theory of interconnection between broader social processes (Eisenhardt 2002) and straddle the continuum between overt researcher and covert participant. Dewalt and Dewalt (1998) find a dual benefit to participant-observational research, "First, it enhances the quality of the data obtained during fieldwork. Second, it enhances the quality of the interpretation of the data. Participant observation is thus both a data collection and an analytic tool” (p. 264). My experience as a participant during and an observer of Amish homebirth offered a tacit understanding of birth in these communities, in part because it shifted "the ethnographic angle of vision to the everyday lives of women” (Naples and Sachs 2000, 196). As such, my data were initially observational and anecdotal, captured in field notes during and after 
our prenatal visits and the birth itself. My observations were triangulated with my senior midwife, who had worked in Amish communities in Michigan and Pennsylvania for several decades. Because we spent countless hours driving together while visiting her clients, she was able to provide a great deal of local context and cultural specificity to help me understand what I was seeing, and it is from these conversations that my ideas were confected, revised, edited, elaborated, and eventually refined, only to be subjected to further examination at subsequent deliveries. As is the way of qualitative research, I owe my gatekeeper a debt of gratitude, and one that I attempted to repay through tireless work as her apprentice (Jolly 2014a).

Being actively involved in prenatal care, labor and delivery, and postpartum visits made it possible to gain a more holistic appreciation of what birth means and offered insight into the Amish's everyday knowledge of how their world works (Smith 1987). It also normalized my presence in Amish life and allowed me the time to think more broadly about the social processes at work (Eisenhardt 2002) in the specific childbirth practices I was observing. Below, I draw on my ethnographic data to offer a sociological reading of the previously mentioned health research observations. In particular, I direct your attention to two features of Amish birth that are pertinent to the argument I am making here. First, I offer some background on how Amish women labor, and discuss some of their specific labor and delivery practices. Second, and related, I offer a review of the role of the midwife (and my role as an apprentice midwife) to begin surfacing some of the differences between Amish and non-Amish childbirth. I offer a brief sketch of Amish birth as a way to illustrate these points and then compare these features with those that characterized non-Amish births.

A call to the midwife signaled active labor, as an Amish woman would rarely require her midwife's assistance during early labor. Amish women spend the early stages of labor working in the home; cooking, cleaning, and completing other daily chores. The midwife would only be summoned after labor intensified, and many times we would arrive at a home with very little time to spare before the baby was born. Amish women are active during their labors, and walked, squatted, and moved around with great frequency, even when delivery was imminent. The midwife supplied a birth-stool, and used this low, padded horseshoe-shaped seat to support her clients in a deep squat. During delivery, an Amish husband would often sit behind his wife, offering his knees as an armrest and lifting her if she needed to change position. Labors and deliveries were quiet, with very little of the loud vocalizations that characterize mainstream depictions of childbirth. One first time mother, after a particularly long and arduous labor, asked if she was the quietest that we had seen. Upon leaving, she asked with pride that we tell her mother about her fortitude during delivery. Permeating this relative silence during birth was often conversation happening between contractions, sometimes including light banter between a laboring woman, her husband, and her midwife. "I can't believe that Eve ate that apple!” joked one first time mother after a difficult contraction. Other times, the musings were more existential. "How many women have sat here before me?” wondered another. The set up for delivery was simple, instruments were sterilized in boiling water, and birth was illuminated with a propane 
lamp. I often wore a battery powered headlamp, the subject of much discussion. Babies were born on the birth-stool, often in the living room with medical pads covering the floor. Umbilical cords were not cut until they had ceased pulsing, and this honor was usually left for the father. ${ }^{4}$ Very few women necessitated sutures to repair vaginal tearing. Mother and baby were then moved to their bed, and the father usually left to fetch help or to return to work within the hour. Their rapid departure was further evidence of birth's normality in Amish life. Left on our own, the midwife and I would clean up and prepare food for the new mother (usually eggs) and hand her care over to another individual, often her mother.

Much of my time during labor was spent separate from the laboring Amish women whom I was assisting. We were often installed in a different room, sequestered on a porch, or otherwise distanced from the birthing woman. Rarely were we called upon to offer direct labor support. Instead, our role was to be as invisible as possible. Indeed, even our cars were hidden from view; such is the Amish desire to maintain secrecy around pregnancy and delivery. We spent our time charting labor's progress while maintaining a sense of distance and privacy. The midwife would listen (often through walls) for changes in a woman's vocalizations, and would wait to step in until she had an indication that delivery was imminent. Only then would she direct her client to the birth-stool; often no internal examination of cervical dilation was necessary. Our primary work came during delivery, and the midwife would lay on the floor in order to assist with the baby's birth. It is here that the midwife would assume a more central role and would talk women through contractions, directing them when to push, how to push, and when to cease pushing to allow for a more gentle delivery. All babies were born head down and healthy, including the surprise birth of a six-fingered dwarf. One mother was transferred to a local hospital for a high level of bleeding (having delivered very quickly before we arrived) and one woman was transferred for failure to progress, resulting in an eventual cesarean delivery. When asked about their nonplussed approach to birth, Amish women would reply, “That’s just our way.” As I attended more deliveries, I became interested in how the parameters of Amish society fostered this unique approach to childbirth, an event that non-Amish women approach with such fear and trepidation.

The ancillary role that we played in Amish deliveries existed in direct opposition to our role at non-Amish births. Because the midwife also served a non-Amish population interested in delivering at home, I was able to attend several English (non-Amish) homebirths during the research period. These births were marked by a high level of midwife involvement, from the initial call at early signs of labor to an intense level of labor support during delivery. In one memorable birth, a laboring mother resisted the midwife's attempt to quickly leave to use the bathroom. So dependent was she on her midwife's support to get through her delivery that she could not imagine even a few minutes of laboring without her midwife. And while this depiction may offer an extreme characterization of non-Amish homebirth, it nonetheless illuminates a central feature of English birth, namely women's high level of dependency on their midwife to mitigate a more general lack of body confidence. “I can’t do it” was a common mantra repeated 
over and over during English labor, and we worked to actively support women through each contraction. Rarely was there the sense that birthing women possess the fortitude to go-it-alone, and instead, the midwife would provide a running dialogue of supportive encouragements throughout the labor. Even prenatal visits were peppered with discussions of pain management strategies, and an unmedicated homebirth was cast as an against-all-odds endeavor rather than as a normal event. Perhaps the most succinct indicator of the differences between Amish and nonAmish experiences of homebirth was the midwife's fee: she charged her Amish clients only 2/3 the amount charged to non-Amish clients. This was not motivated by charity on her part; it merely reflected the amount of work required. In attending these births, and in moving between Amish and non-Amish spaces, it became plain to see how labor and delivery was socially shaped, and the fingerprints of each society were everywhere visible.

\section{A Sociological Analysis of Amish Femininity}

Much like the Amish say of themselves, childbirth has been taken to be "in this world but not of it," meaning that while birth is a central feature of life, it is not one that is seen as being explicitly influenced by the social landscape. Childbirth is largely regarded as a physiological event. Despite this tendency to reduce childbirth to its biologic features, cultural anthropologists and sociologists have long argued that birth is a "socially embedded experience" (Behruzi, et al. 2013, 206) and one that is "everywhere socially marked and shaped” (Jordan and Davis-Floyd 1993, 1). For the Amish, childbirth was tied to what it means to be a woman within Amish society and cannot be understood apart from a more sociological analysis of Amish gender socialization. From my data and analysis, I concluded that childbirth was emblematic of a culturally-specific definition of womanhood in that it aligned with a more general Amish discourse about work. For both Amish women and men, hard work is celebrated, "[w]ork is not just a way of getting something done; it makes a statement about one's faith and identity." (Kraybill and Bowman 2001, 199). In "provid[ing] a blueprint for an orderly way of life” (Kraybill 2001[1989], 15), the Ordnung stresses this notion that "[w]ork is more satisfying than consumption" (Kraybill 2001[1989], 19) and that "labors that produce a tangible result" (Kraybill and Bowman 2001, 194) are always more valued over those that do not. For an Amish woman in particular, her identity as an Amish woman is realized through her ongoing engagement with and mastery of physical tasks. Working hard is part and parcel of being an Amish woman, and girls and women are socialized to equate femininity with physicality. As a result, Amish women have a high level of body confidence and surety in their body's ability to triumph in the face of physical adversity.

Childbirth offered Amish women an opportunity to engage in and succeed at physically difficult work. Labor (read: childbirth) provided Amish women with an opportunity to labor (read: work) (Jolly 2015). An Amish woman’s capacity for successful labor (both during childbirth and otherwise) was an integral part of Amish femininity. Within a society where women's bodies are cast as capable, the strength and the pain tolerance that unmedicated birth 
necessitated did not exist in opposition to femininity but instead became emblematic of it. Indeed, Amish homebirth was "just our way" in that it was grounded in a social practice that Amish women found very familiar; one that married physical fortitude with body confidence. Within the context of Amish society, femininity was equated with physicality and stoicism, both specifically during childbirth and more widely in daily life. Amish birth, then, reflects an Amish socialization that cannot be understood without a careful consideration of Amish sociocultural life. A woman's ideas about physical work, and confidence in her body's ability to do that work, are inexorably tied to how her society thinks about women's work and about women's bodies. In the Amish communities that we served, Amish women approached childbirth as they approached other physically difficult tasks, with a high level of body confidence and a self-assuredness that they could accomplish this largely on their own. The brevity of Amish labors, Amish women's fortitude in the face of unmedicated homebirth, their lack of fear, their ability to manage a high level of pain - in short, all of the features of Amish birth that have so interested health researchers - cannot be fully understood without a sociological investigation of Amish life. Femininity shapes woman, body, and mind. When Amish birth practices were examined in light of the sociocultural landscape and triangulated through local expertise, the consequences of Amish women's unique gender socialization became obvious.

Childbirth is thoroughly shaped by the society in which birthing women live (Liamputtong 2005). Yet, without a sustained analysis, the observations health researchers make of the Amish offer little in the way of academic insight. Excused as cultural anomalies or sidebars, the explanatory power of these observations is often lost or overlooked. This is true even for scholarship outside Amish and plain Anabaptist studies, and includes the wider social science audiences related to the fields of geography, sociology, anthropology, and history. For example, feminist sociologists would likely find interesting the results of the comparative study on women's likelihood of seeking out breast and cervical cancer screenings. In it, Documét, et al. (2008) note in passing that "Amish participants did not express embarrassment [about undergoing medical tests], but all other groups did” (p. 62). This lack of bodily embarrassment offers a candid response to substantial research on non-Amish women's shame that casts it as a "primary structure of a woman's lived experience" and one that "becomes integral to a generalized sense of inferiority of the feminine body-subject” (Kruks 2001). Further investigation is necessary to discover whether these particular findings challenge long held feminist theories that universalize women's body shame. Ongoing Amish health research may offer passing observations that—when thoroughly researched—have the power to challenge commonplace assumptions that have served as cornerstones of our scholarly traditions.

Bodies no longer belong solely to the biologists, the health scientists, and the medical researchers. The power of socialization is seen to be a force that "reaches into the very grain of individuals, touches their bodies and inserts itself into their actions and attitudes, their discourses, learning processes and everyday lives” (Foucault 1980, 39). The body now plays a significant role in our understanding of society and social relations, and ongoing attention has 
been focused at the Venn where body, power, and society intersect. In contemporary scholarship, the body is seen as a primary site where social relations of power are reproduced (Hancock, et al. 2000) and scholars have asserted that "bodies have all the explanatory of minds" (Grosz 1994, vii). The body is not pre-social or innate, but is recognized as being shaped by social discourses, cultural practices, and the long reach of historical traditions. And as social scientific research continues to take the body as a central site of inquiry, plain Anabaptist scholarship (in conjunction with Amish health studies and the theorizations they make possible) seems well positioned to heed the call "for more research, for example, on embodied subjectivities - forms of embodiment linked to subjectivity, desire, ways of seeing and acting in the world particularly within less explored social and cultural contexts and toward the comparative" (Adelman and Ruggi 2016, 922). This growing enthusiasm for embodied research has surfaced alongside a greater awareness of the dangers associated with averting our academic gaze away from the body.

As I evidenced here, a neglect of cultural specificity and socialization's particulars in Amish health research risks missing the connection between Amish birth practices and Amish gender norms. More generally, it overlooks the possibility for deepening our understanding of how sociocultural differences shape physical bodies. For mainstream health researchers hoping to improve childbirth outcomes (shorten labors, reduce women's fear, and decrease the need for medical intervention), this research suggests that mainstream patterns of gender socialization may be a point of departure (Jolly 2014b; Jolly 2015). And as national (Anderson 2004; Declercq, et al. 2014) and international (WHO 2015) attention is increasingly focused on addressing concerns around mainstream childbirth practices, lessons from the Amish are newly relevant again. Childbirth is just one potential site for richly embodied analysis of the social world, and Amish health research has much to offer a wide array of social science scholarship. "There is no such thing [...] as the purely 'natural' body, the body that may be separated from society and culture" (Lupton 1999, 50). Our ongoing realizations of how ideas shape experiences promises to be a fruitful avenue for research. Women's reproductive health research is not the only field to offer potential for this sort of cross-pollination; indeed, much of the Amish health research happening today deserves to be put into conversation with sociocultural scholarship on Amish society, plain Anabaptist communities, and plain Anabaptist cultural traditions more generally.

\section{Implications}

As health researchers gain greater access to Amish populations and continue to dedicate resources to systematically studying Amish lives, we can anticipate Amish health findings will ever more pepper the pages of medical journals. I have argued here that plain Anabaptist scholars have something meaningful to contribute to this growing field, and their sociocultural expertise will likely offer a much needed counterbalance to the perfunctory conclusions that are often drawn from such studies. In particular, health research has relied on cursory descriptions of 
Amish life, characterized in one cancer study as simply a "lifestyle which does not include watching television, using computers, using automated farm equipment or automobiles” (Katz, et al. 2012, 435). Alternatively, authors point to the "strong social structure" (Rogers et al. 2013, 918) of their Amish patients, their "close knit familial units” (McArdle, et al. 2006), with little in the way of what that actually means. One such study wonders if "changes observed in the nature of farm work accompanying mechanization may further complicate the relationship between [farming] occupation and physical activity.” (Katz, et al. 2012, 439) Another study concludes that their findings on longevity could "simply reflect happier marriages, which may in turn be associated with extended life span” or may involve a more pragmatic measure of one's social network (McArdle, et al. 2006, 194). Yet another study asks whether "the maintenance of productive roles and extensive social support" of Amish elders is a cause for their reduced mortality rate (Hewner 2001, 529). Plain Anabaptist scholarship seems well prepared to think deeply about such speculation, to offer a reasoned response to these findings, and to foreground the social and cultural features of Amish society that likely remain invisible to health researchers.

Indeed, plain Anabaptist scholars would likely raise an eyebrow at the assertion that being Amish could be distilled down to a set of variables associated with technology use, farm mechanization, or one's social network. The deeply historical, culturally nuanced, ethnographic studies that have come out of qualitative plain Anabaptist scholarship suggest that the process of Amish socialization cannot always be condensed into a tidy matrix or specified as a set of variables. Yet, in our attempt to consider the architectural vastness of Amish life, we may have missed opportunities to render key components of Amish life transparent to those outside the field. Being Amish means more than having a strong social structure or a close knit familial unit, and it is incumbent upon plain Anabaptist scholars to specify the relevant social practices that may stand in for being Amish. The growing focus on comparative research suggests that doing so is necessary if we are interested in remaining central to conversations about the Amish, and what mainstream society can learn from them. As health researchers, statisticians, and others continue to juxtapose Amish and non-Amish societies, our ability to translate plain Anabaptist scholars' understanding of Amish culture to a wider audience will be of increasing import.

The reach and scope of health research suggests it offers the reciprocal possibility of bringing new ideas into current discussions of Amish life. With its large sample sizes and relatively low cost of entry, health-related survey data have the potential to shine a light on topics that have previously remained obscured. By way of example, Miller, et al. (2007) offers this aside in their discussion of women's health behaviors:

Of the 249 Amish women who responded to questions of birth control, 52 (20.9\%) said they were currently using birth control. Condoms are the most frequently used form of birth control, used by 26 of 52 (50\%) Amish women and their partners who use birth control. (p. 168)

Certainly this finding is of pharaonic import to Amish scholars interested in the changing structure of Amish society, the porous nature of the boundaries between Amish and non-Amish 
worlds, and the ways that individuals exercise agency within the formal dictates of Church doctrine. Amish have long been taken to be a "natural fertility population" (Greksa 2002), and birth control avoidance is a central claim in many theories of Amish life (Hostetler 1993[1963]; Kraybill 2001[1989]) despite growing evidence of condom use (Jolly 2014a). The passing observations made in health research on the Amish may illuminate new realities that have much to offer existing plain Anabaptist scholarship. Findings that report low rates of intimate partner violence among the Amish, their high levels of reported mental health and lower rates of depression, and Amish women's high level of body confidence and their aversion to unhealthy patterns of weight loss, all suggest that the social structure of Amish life shapes the health and bodies of the Amish in academically-interesting and socially-relevant ways. Pairing observations of Amish heath practices with cultural analyses of Amish society offer a means by which we can move beyond a passing nod to the plain ways of Amish life and delve more deeply into the specific features of Amish society that foster health and wellness. This cross-pollination has the potential to infuse plain Anabaptist scholarship in new and exciting ways, particularly if we can begin to offer language, concepts, and ideas that can subsequently inform health scholarship. Much hay is to be made here; the terrain is intellectually fertile, and the new thoughts and perspectives generated by this intersection promises to revivify more established bodies of plain Anabaptist knowledge.

\section{Endnotes}

${ }^{1}$ Contact information: Natalie Jolly, School of Interdisciplinary Arts and Sciences, University of Washington Tacoma 1900 Commerce St, Tacoma, WA 98402; natjolly@uw.edu

${ }^{2}$ Health was constructed as a measure of birth weight, gestational age, 1 min Apgar score, and 5 min Apgar score.

${ }^{3}$ Women often shared stories about delivering "before they had time to get their pins out," i.e. before they had time to unpin their apron and their bonnet. (In a process I watched with utter fascination, straight pins are woven through the hair to affix a woman's bonnet.)

${ }^{4}$ I was invited to cut the cord of a baby whom I helped deliver on my birthday.

\section{References}

Adelman, Miriam, and Lennita Ruggi. 2016. “The Sociology of the Body.” Current Sociology 64(6):907-30. https://doi.org/10.1177/0011392115596561

Anderson, G.M. 2004. "Making Sense of Rising Caesarean Section Rates.” BMJ: British Medical Journal 329(7468):696-97. https://doi.org/10.1136/bmj.329.7468.696

Behruzi, Roxana, Marie Hatem, Lise Goulet, William Fraser, and Chizuru Misago. 2013. "Understanding Childbirth Practices as an Organizational Cultural Phenomenon: a Conceptual Framework.” BMC Pregnancy and Childbirth 13(205):1-10. 
Bing, Elisabeth. 2002. “Lamaze Childbirth among the Amish People.” The Journal of Perinatal Education 11(2):13-22.

Campanella, Karla, Jill Korbin, and Louise Acheson. 1993. "Pregnancy and Childbirth among the Amish.” Social Science \& Medicine 36(3):333-42. https://doi.org/10.1016/02779536(93)90017-X

Cox, Kima, Ruth Schlegel, Patt Payne, Dusty Teaf, and Leah Albers. 2013. “Outcomes of Planned Home Births Attended by Certified Nurse-Midwives in Southeastern Pennsylvania 1983-2008.” Journal of Midwifery \& Women's Health 58(2):145-49. https://doi.org/10.1111/j.15422011.2012.00217.x

Declercq, Eugene., Carol Sakala, Maureen Corry, Sandra Applebaum, and Ariel Herrlich. 2014. "Major Survey Findings of Listening to Mothers III: Pregnancy and Birth.” Journal of Perinatal Education 23(1):9-16. https://doi.org/10.1891/1058-1243.23.1.9

Deline, James, Lisa Varnes-Epstein, Lee Dresang, Mark Gideonsen, Laura Lynch, and John Frey. 2012. "Low Primary Cesarean Rate and High VBAC Rate with Good Outcomes in an Amish Birthing Center.” Annals of Family Medicine 10(6):530-37. https://doi.org/10.1370/afm.1403

Dewalt, Kathleen, and Billie Dewalt. 1998. "Participant Observation.” Handbook of Methods in Cultural Anthropology edited by H. Russell Bernard. Walnut Creek, CA: AltaMira Press.

Documét, Patricia, Heidi Green, Janet Adams, Lou Ann Weil, Jami Stockdale, and Yll Hyseni. 2008. "Perspectives of African American, Amish, Appalachian, and Latina Women on Breast and Cervical Cancer Screening: Implications for Cultural Competence.” Journal of Health Care for the Poor and Underserved 19:56-74. https://doi.org/10.1353/hpu.2008.0018

Eisenhardt, Kathleen. 2002. "Building Theories from Case Study Research.” Pp. 5-36 in The Qualitative Researcher's Companion, edited by A. Michael Huberman and Matthew Miles. Thousand Oaks, CA: Sage Publications.

Foucault, Michel. 1980. Power/Knowledge: Selected Interviews and Other Writings 1972-1977. Colin Gordon, et al., (trans.). New York, NY: Pantheon.

Greksa, Lawrence. 2002. "Population Growth and Fertility Patterns in an Old Order Amish Settlement.” Annals of Human Biology 29(2):192-201. https://doi.org/10.1080/03014460110075684

Grosz, Elizabeth. 1994. Volatile Bodies. Bloomington, IN: Indiana University Press.

Hairston, Kristen, Julie Ducharme, Margarita Trueth, Wen-Chi Hsueh, Ania Jastreboff, Kathy Ryan, Xiaolian Shi, Braxton Mitchell, Alan Shuldiner, and Soren Snitker. 2013. "Comparison of BMI and Physical Activity between Old Order Amish Children and Non-Amish Children.” Diabeties Care 36(April):873-78. https://doi.org/10.2337/dc12-0934

Hancock, Philip, Bill Hughes, Elizabeth Jagger, Kevin Peterson, Rachel Russell, Emmanuelle Tulle-Winton, and Melissa Tyler. 2000. The Body, Culture, and Society: An Introduction. Philadelphia, PA: Open University Press. 
Hewner, Sharon. 2001. "Postmenopausal Function in Context: Biocultural Observations on Amish, Neighboring Non-Amish, and Ifugao Household Health.” American Journal of Human Biology 13(4):521-30. https://doi.org/10.1002/ajhb.1084

Hostetler, John 1993[1963]. Amish Society. Baltimore, MD: Johns Hopkins University Press.

Jolly, Natalie. 2010. “Childbirth.” Pp 183-89 in The Encyclopedia of Motherhood, Vol 1. Edited by Andrea O'Reilly. Thousand Oaks, CA: Sage. https://doi.org/10.4135/9781412979276.n99

Jolly, Natalie. 2014a. "In This World but Not of It: Midwives, Amish, and the Politics of Power.” Sociological Research Online 19(2):1-13. https://doi.org/10.5153/sro.3294

Jolly, Natalie. 2014b. “Amish Femininity: New Lessons from the Old Order.” Journal of the Mothering Initiative 5(2):75-90

Jolly, Natalie. 2015 “Does Labor Mean Work? Queries into the Role of Femininity in Childbirth.” Pp. 218-231 in Natal Signs: Cultural Representations of Pregnancy, Birth, and Parenting edited by Nadya Burton. Toronto, ON: Demeter Press. https://doi.org/10.2307/j.ctt1rrd8tc.16

Jordan, Brigette. 1983. Birth in Four Cultures: A Crosscultural Investigation of Childbirth in Yucatan, Holland, Sweden, and the United States ( $3^{\text {rd }}$ ed.). Montreal, Quebec: Eden Press.

Katz, Mira, Amy Ferketich, Benjamin Broder-Oldach, Amy Harley, Paul Reiter, Electra Paskett, and Clara Bloomfield. 2012. "Physical Activity among Amish and Non-Amish Adults Living in Ohio Appalachia.” Journal of Community Health 37(2):434-40. https://doi.org/10.1007/s10900011-9460-9

Keeslar, Irena. 2011. "Birth with the Amish: A Unique Experience.” Midwifery Today (97):46-68.

Kraybill, Donald. 2001[1989]. The Riddle of Amish Culture. Baltimore, MD: Johns Hopkins University Press.

Kraybill, Donald, and Carl Desportes Bowman. 2001. On the Backroad to Heaven: Old Order Hutterites, Mennonites, Amish, and Brethren. Baltimore, MD: Johns Hopkins University Press.

Kroening Emily and Therese Zink. 2008. “Learning from an Amish Birth.” Family Medicine 40(2):91-92.

Kruks, Sonia. 2001. Retrieving Experience: Subjectivity and Recognition in Feminist Politics. Ithica, NY: Cornell University Press.

Lemon, Betty Spencer. 2006. “Amish Health Care Beliefs and Practices in an Obstetrical Setting.” Journal of Multicultural Nursing \& Health 12(3):54-59.

Liamputtong, Pranee. 2005. "Birth and Social Class: Northern Thai Women's Lived Experiences of Caesarean and Vaginal Birth.” Sociology of Health \& Illness 27(2):243-

70. https://doi.org/10.1111/j.1467-9566.2005.00441.x 
Lucas, Cheryl, Robert O'Shea, Maria Zielezny, Jo Freudenheim, and James Wild. 1991. "Rural Medicine and the Closed Society: Pregnancy Outcomes among Amish and Non-Amish Women.” New York State Journal of Medicine 91:49-52.

Lupton, Deborah. 1999. “The Social Construction of Medicine and the Body.” Pp. 50-63 in The Handbook of Social Studies in Health and Medicine edited by Gary Albrecht, Ray Fitzpatrick, and Susan Scrimshaw. Thousand Oaks, CA: Sage.

McArdle, Patrick, Toni Pollin, Jeffrey O'Connell, John Sorkin, Richa Agarwala, Alejandro Schaefer, Elizabeth Streeten, Terri King, Alan Shuldiner, and Braxton Mitchell. 2006. "Does Having Children Extend Life Span? A Genealogical Study of Parity and Longevity in the Amish.” Journals of Gerontology Series A: Biological Sciences \& Medical Sciences 61(2):19095. https://doi.org/10.1093/gerona/61.2.190

Miller, Kirk, Berwood Yost, Sean Flaherty, Marianne Hillemeier, Gary Chase, Carol Weisman, and Anne-Marie Dyer. 2007. "Health Status, Health Conditions, and Health Behaviors among Amish Women: Results from the Central Pennsylvania Women's Health Study (CePAWHS).” Women's Health Issues 17:162-71. https://doi.org/10.1016/j.whi.2007.02.011

Miller, Nancy. 1997. "Childbearing Health Practices as Described by Old Order Amish Women.” M.S. thesis. East Lansing, MI: Michigan State University.

Naples, Nancy, and Carolyn Sachs. 2000. "Standpoint Epistemology and the Uses of SelfReflection in Feminist Ethnography: Lessons for Rural Sociology.” Rural Sociology 65(2):194214. https://doi.org/10.1111/j.1549-0831.2000.tb00025.x

Rogers, Amelia, Michael Horst, Frederick Rogers, John Lee, and Michael Reihart. 2013. “From the Barn to the Operating Room and Back: The Amish Way of Life Leads to Improved Throughput and Outcomes Following Trauma.” Journal of Trauma and Acute Care Surgery 75(5):916-18. https://doi.org/10.1097/TA.0b013e3182a6864e

Showalter, Anna. 2000. “Birthing among the Amish.” International Journal of Childbirth Education 15(4):10-11.

Smith, Dorothy. 1987. The Everyday World as Problematic: A Feminist Sociology. Boston, MA: Northeastern University Press.

Thomas, Melissa, Usha Menon, Steven Ferguson, and Margaret Hiermer. 2002. "Health-Related Research among Amish Women: A Review of Findings.” Current Women's Health Reports 2:208-13.

VonDerAhe, Elizabeth.1998. “Trusting Birth: Amish Style.” The Birthkit: A Publication of the Midwifery Today Association 17(2):10-12.

Von Gruenigen, Vivian, Anna Showalter, L. White, M. Hopkins, M. Mazi, and E.L. Jenison. 2000. "Amish and Non-Amish Women's Use of Complementary and Alternative Medicine.” 
Conference abstract. International Journal of Gynecology and Obstetrics 70(1):101. https://doi.org/10.1016/S0020-7292(00)83303-2

Weyer, Sharon, Victoria Hustey, Lesley Rathbun, Vickie Armstrong, Samantha Reed Anna, Jeanna Ronyak, and Carol Savrin. 2003. “A Look into the Amish Culture: What Should We Learn?” Journal of Transcultural Nursing 14(2):139-45. https://doi.org/10.1177/1043659602250639

World Health Organization. 2015. "Caesarean Sections Should Only be Performed When Medically Necessary.” Retrieved from http://www.who.int/mediacentre/news/releases/ 2015/caesarean-sections/en/

Williams, Jennifer. 2003. “An Amish Birth Story.” The Birthkit: A Publication of the Midwifery Today Association 38(2):1-11. 